\title{
Association of Polymorphisms of the Matrix Metalloproteinase 9 Gene with Ischaemic Stroke in a Southern Chinese Population
}

\author{
You Lia Linfa Chen ${ }^{\mathrm{b}}$ Shaoyu Yao ${ }^{\mathrm{d}}$ Jianya Chen ${ }^{\mathrm{b}}$ Weidong $\mathrm{Hu}^{\mathrm{b}}$ \\ Mengxu Wang ${ }^{b}$ Shaofeng Chen ${ }^{b}$ Xinglan Chen ${ }^{b}$ Shengnan $\mathrm{Li}^{a} \quad$ Xuefeng Gu \\ Guoda Ma ${ }^{a}$ Bin Zhao ${ }^{a, c}$ Wangtao Zhong ${ }^{b}$ Keshen Li,c \\ aGuangdong Key Laboratory of Age-Related Cardiac and Cerebral Diseases, Affiliated Hospital of \\ Guangdong Medical University, ${ }^{b}$ Department of Neurology, Affiliated Hospital of Guangdong Medical \\ University, c Institute of Neurology, Affiliated Hospital of Guangdong Medical University, dDepartment \\ of Nursing, Affiliated Hospital of Guangdong Medical University, China
}

\section{Key Words}

MMP9 • Ischaemic stroke • Polymorphism

\begin{abstract}
Background/Aims: Matrix metalloproteinase 9 (MMP9), a potent endopeptidase degrading extracellular matrix, plays a pivotal role in the pathogenesis of ischaemic stroke (IS). The present study was undertaken to determine the association of MMP9 gene polymorphisms and the risk of IS in a southern Chinese population. Methods: A cohort of 1274 patients and 1258 agematched healthy controls were genotyped to detect the four MMP9 polymorphisms (rs17156, rs3787268, rs3918241 and rs3918242) using SNaPshot. Results: Our study demonstrated a significant difference in the genotype and allele frequencies of the MMP9 rs3918242 polymorphism between the IS patients and the controls $(P=0.012$ for the genotype and $P=$ 0.0092 for the allele). Stratification by smoking status showed statistically significant differences in the frequency and allele of the rs3918242 polymorphism between IS patients and the controls $(P=0.0052$ for the genotype and $P=0.0019$ for the allele). Further stratification by IS subtypes revealed that the presence of the T allele of the MMP9 rs3918242 polymorphism confers a higher risk of the large artery atherosclerosis subtype of IS $(P=0.017)$. Moreover, IS patients with the rs3918242 T allele of MMP9 presented with increased serum MMP9 production, and this increase was more significant in smokers with IS $(P=0.022)$. Patients carrying the variant T allele of the MMP9 rs3918242 polymorphism exhibited significantly higher infarct volumes than those with the major $C C$ genotype $(P=0.036)$. Conclusion: Our study provides preliminary evidence that the MMP9 rs3918242 polymorphism is linked to a

Y. Li and L. Chen have contributed equally to this work.

\begin{tabular}{ll}
\hline Keshen Li & Institute of Neurology, Affiliated Hospital of Guangdong Medical University \\
and Wangtao Zhong & Zhanjiang, Guangdong 524001 (China) \\
& E-Mail keshenli1971@163.com; wangtaozhong8@163.com
\end{tabular}
\end{abstract}




\section{Cellular Physiology Cell Physiol Biochem 2018;49:2188-2199

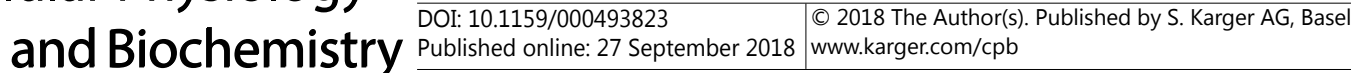 \\ Li et al.: MMP9 Polymorphisms and Ischaemic Stroke}

higher risk of IS, confirming the role of MMP9 in the pathophysiology of IS, with potentially important therapeutic implications.

\section{Introduction}

Stroke is the second most common cause of death worldwide and is the leading cause of long-term disability in developing and developed countries [1]. Approximately $80 \%$ of strokes are ischaemic in origin. In China, there are more than one million people who die from stroke-related diseases every year. Multiple factors, including hypertension, diabetes, smoking, hyperlipidaemia, and hyperhomocysteinemia, are associated with a higher risk of stroke [2]. However, these risk factors can only explain a small part of the aetiology. A large body of scientific research has indicated that gene polymorphisms modulate the pathophysiological processes of IS and confer a small to moderate risk [3-5].

Matrix metalloproteinases (MMPs) are a family of proteolytic zinc-dependent enzymes whose main function is to degrade and deposit structural proteins within the extracellular matrix (ECM) in both physiological and pathological process [6]. MMPs play a pivotal role in early atherosclerosis, vascular remodelling, and development of arterial plaque rupture [7, 8]. Among MMPs, MMP9 is the most widely investigated enzyme in acute ischaemic stroke (IS), and its expression is rapidly upregulated after cerebral ischaemia [9, 10]. MMP9 is highly expressed in the vulnerable regions of atherosclerotic plaques, contributing to the weakening of the plaques' fibrous cap and to the development of acute ischaemic events resulting from plaque rupture and thrombus formation. This appeared to play a pivotal role in vascular remodelling, development of atherosclerotic lesions and arterial plaque rupture $[6,11,12]$. A very recent prospective study reported that higher serum MMP9 levels in the acute phase of IS were associated with increased risk of mortality and major disability, suggesting that serum MMP9 could be an important prognostic factor for IS [13].

The human MMP9 gene is located on the long arm of chromosome 20 (20q11.1-13.1), and some important functional polymorphisms have been reported $[14,15]$. The $-1562 \mathrm{C} / \mathrm{T}$ polymorphism (rs3918242) located in the MMP9 gene promoter has been reported to be associated with higher MMP9 circulating levels [16]. The -1562C/T polymorphism of MMP9 has been reported to play a role in the development of a number of diseases, including coronary heart disease (CHD) [17], myocardial infarction (MI) [18] and IS [19]; however, the results are inconclusive. A meta-analysis suggests that the $M M P 9-1562 \mathrm{~T}$ allele is a risk factor for CHD [17]. Another meta-analysis performed by Juan et al. indicates that the MMP9 -1562 $\mathrm{C} / \mathrm{T}$ polymorphism is a risk factor associated with increased risk of MI in white ethnicity, but not in Asian population [18]. Contrarily, Wang et al. reported that MMP9-1562 C/T was significantly associated with increased risk for MI in Asian population, but not in Western population [20]. This discrepancy might result from demographic and profound ethnic differences. Moreover, the association between other $M M P 9$ polymorphisms and the risk of IS is insufficiently investigated. Therefore, we carried out a case-control study to determine the role of $M M P 9$ polymorphisms in the development of IS in a southern Chinese population.

\section{Materials and Methods}

\section{Study population}

In this case-control study, 1274 IS patients (mean age, $66.87 \pm 10.60$ years) were recruited from the Department of Neurology, Affiliated Hospital of Guangdong Medical University, between 2013 and 2017. All the patients were identified as having newly diagnosed IS by at least two independent neurologists, according to the clinical signs and symptoms. All patients underwent computed tomography (CT) scans and/or magnetic resonance imaging (MRI) as well as standardized blood tests. Based on the clinical manifestations and neuroimaging data, two neurologists classified all ischaemic strokes into subtypes based on the Chinese IS subclassification (CISS) system [21]. Patients with a history of transient ischemic attacks, 


\section{Cellular Physiology Cell Physiol Biochem 2018;49:2188-2199 \begin{tabular}{ll|l} 
and Biochemistry Published online: 27 September 2018 & $\begin{array}{l}\text { (c) } 2018 \text { The Author(s). Published by S. Karger AG, Basel } \\
\text { www.karger.com/cpb }\end{array}$ \\
\hline
\end{tabular}}

Li et al.: MMP9 Polymorphisms and Ischaemic Stroke

peripheral vascular diseases, coronary artery diseases, autoimmune diseases, systemic inflammatory diseases, blood diseases, or malignant tumours were excluded from this study. One subject diagnosed with recurrent stroke was also excluded.

The healthy control group consisted of 1258 individuals ( $65.55 \pm 9.11$ years) who were recruited from the Health Examination Center of the Affiliated Hospital of Guangdong Medical University during the same time period, and these control subjects were comparable to the IS subjects in terms of age and race. Control subjects did not have a recent history of cerebrovascular disease or MI. The same exclusion criteria were used as above.

Smokers were patients who smoked more than 10 cigarettes per day for five years, and hypertension was defined as having a systolic pressure $>130 \mathrm{~mm} \mathrm{Hg}$ and a diastolic pressure $>80 \mathrm{~mm} \mathrm{Hg}$ (stage 1) on more than one occasion [22] and included patients currently taking antihypertensive medications. Diabetes mellitus was defined as a fasting plasma glucose level $>126 \mathrm{mg} / \mathrm{dL}(7.0 \mathrm{mmol} / \mathrm{L})$ and included patients taking antidiabetic medications. Written informed consent was obtained from each participant prior to enrollment in the study. The study was approved by the Ethics Committee of Guangdong Medical University.

\section{Genotyping}

Genomic DNA was extracted from peripheral blood leukocytes using the EZ-10 Spin Column Whole Blood Genomic DNA Isolation Kit (Sangon Biotech ${ }^{\circledR}$, Shanghai, China) according to the manufacturer's instructions. The DNA concentration was determined using a DNA spectrophotometer (ND-1000, NanoDrop, Wilmington, USA).

The four MMP9 SNPs (rs17576, rs3787268, rs3918241 and rs3918242) were selected based on previous studies [19, 23, 24]. The selected MMP9 SNPs were genotyped using the SNaPshot Multiplex Kit (Applied Biosystems Co., Ltd., Foster City, CA, USA), and the primers for PCR amplification and SNaPshot extension were designed based on the GenBank database. The primers used in the SNaPshot were as follows: rs17576F: ACGTTGGATGTGGGGGTTATAATGTGCTGT, rs17576R: ACGTTGGATGTGGAAGTGAATGGAAACTG, rs3787268F: ACGTTGGATGATCCTGGGCCATAGAGGATG, rs3787268R: ACGTTGGATGTCCTCACTCAGCCTCCСTT, rs3918241F: ACGTTGGATGTCGTGACTGCAAAGCAGATG, rs3918241R: ACGTTGGATGAATGAGACTGTGAGATGGAG; rs3918242F: ACGTTGGATGCCTCCCGAGTAGCTGGTATT, rs3918242R: ACGTTGGATGCCTGGTCAACGTAGTGAAAC. The SNaPshot reactions and PCR procedures were performed as previously described [25].

\section{Enzyme-linked immunosorbent assay (ELISA)}

Blood samples were collected as soon as the diagnosis was established. Blood specimens were drawn in EDTA-containing tubes and centrifuged at low speed, and the serum aliquots were stored at $-20^{\circ} \mathrm{C}$. The serum MMP9 levels were determined in duplicate using the Quantikine sandwich ELISA kits (R\&D Systems, Minneapolis, MN, USA) according to the manufacturer's instructions.

\section{Infarct volume quantification}

Infarct volumes indicated by diffusion-weighted magnetic resonance imaging (DWI) were measured with MIPAV software (Medical Image-Processing, Analysis, and Visualization, version 3.0; NIH, Bethesda, MD) [26]. Acute diffusion lesions were defined on a slice-by-slice basis using a semiautomatic segmentation approach, consulting apparent diffusion coefficient and fluid-attenuated inversion recovery imaging sequences to distinguish acute from non-acute diffusion change. DWI infarct volumes were calculated by multiplying the slice thickness by the total lesion area.

\section{Statistical Analyses}

All statistical tests were performed using the SPSS 19.0 software program (IBM, Armonk, NY, USA). The Hardy-Weinberg equilibrium of the SNPs was examined using a chi-squared test to compare the observed genotype frequencies with the expected frequencies among the control subjects. The baseline characteristics are expressed as the means \pm standard deviation (SD) for the continuous variables, and as the medians and percentage for the quantitative variables. A chi-squared test and Student's t-test were used to compare the variables between the two groups. 


\section{Cellular Physiology Cell Physiol Biochem 2018;49:2188-2199

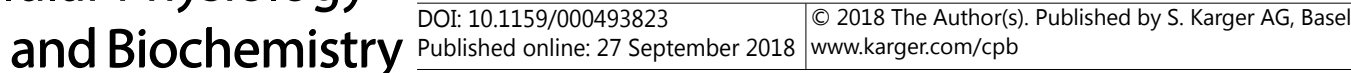 \\ Li et al.: MMP9 Polymorphisms and Ischaemic Stroke}

The allele and genotype frequency differences between the patients and healthy controls were assessed using the $\chi 2$ test or Fisher's exact test. The odds ratio (OR) and 95\% confidence interval (CI) were calculated to assess the correlation between the MMP9 genotype and IS. The comparisons of the serum MMP9 levels among the different MMP9 polymorphisms between the patients and controls were evaluated using Student's t-test for the normally distributed data or a Mann-Whitney-U test for the non-parametric data. Correlations between the genotypes of the MMP9 polymorphisms and the DWI infarct volume were assessed using analysis of variance (ANOVA). Association between the polymorphism and the risk of IS was evaluated using logistic regression analysis and was adjusted by age, gender, smoking, hypertension, diabetes mellitus and hyperlipidaemia. Benjamini-Hochberg $(\mathrm{BH})$ multiple testing correction was applied for multiple comparisons with control type 1 error. The criterion for significance was set at $\mathrm{P}<0.05$ for all of the tests.

\section{Results}

\section{Demographic characteristics}

The demographic characteristics of all of the participants in the study are presented in Table 1 . Of the 2532 participants, 1274 were patients with IS and 1258 were healthy controls. There were no significant differences between the patients and controls in terms of age. The mean age was 66.87 years old ( \pm 10.60 years) for the IS subjects and 65.55 years old $( \pm 9.11$ years) for the control subjects. Significant differences were also found in risk factors, such as gender, smoking status, hypertension, diabetes and hyperlipidaemia. The triglycerides and homocysteine levels tended to be higher in the IS patients than in controls, whereas the highdensity lipoprotein levels were lower at admission in the IS patients. The total cholesterol and low-density lipoprotein levels in the IS patients were not significantly different from those noted in the healthy control subjects.

\section{MMP9 gene polymorphisms and the risk of IS}

The genotype and allele frequencies of the MMP9 polymorphisms are shown in Table 2. No deviation from the Hardy-Weinberg equilibrium for the polymorphisms examined was observed in the genotype distributions of the IS patients and controls (data not shown).

The comparison of genotype distributions between the IS patients and control subjects with the $\chi 2$-test revealed that there was a statistical association $(P=0.012)$ between the rs3918242 polymorphism of MMP9 and the risk of IS. In a dominant model (CT+TT versus $\mathrm{CC}$ ), a significant difference was detected between the IS group and controls (OR $=1.30,95 \%$ CI: $1.07-1.59, \mathrm{P}=0.012$ ). In a recessive model (TT versus $\mathrm{CC}+\mathrm{CT}$ ), a significant difference was observed in the IS group compared with the controls (OR $=2.07,95 \% \mathrm{CI}: 1.11-3.85, \mathrm{P}=0.019)$. The frequency of the $\mathrm{T}$ allele at the rs3918242 polymorphism was significantly different in the IS group compared with the controls $(\mathrm{OR}=1.32,95 \% \mathrm{CI}$ : 1.11-1.59, $\mathrm{P}=0.0092$ ), after $\mathrm{BH}$ correction. However, we failed to find any statistical association between other polymorphisms and the risk of IS.

\section{Haplotype analysis}

Four haplotypes in which the frequency of the haplotype was greater than $5 \%$ in

Table 1. Characteristics of ischemic stroke cases and controls. Continuous data are presented as the mean $\pm \mathrm{SD}$, median (range) or $\mathrm{n}(\%){ }^{\text {a }} \mathrm{P}<0.05$ is indicated in bold font

\begin{tabular}{lccc}
\hline Variables & $\begin{array}{c}\text { IS } \\
(\mathrm{n}=1274)\end{array}$ & $\begin{array}{c}\text { Control } \\
(\mathrm{n}=1258)\end{array}$ & P value \\
\hline Mean age (years) & $66.87 \pm 10.60$ & $65.55 \pm 9.11$ & 0.22 \\
Male/female & $890 / 384$ & $823 / 435$ & 0.017 \\
Smokers, n (\%) & 620 & 382 & $<0.001$ \\
Hypertension, n (\%) & 783 & 528 & $<0.001$ \\
Diabetes, n (\%) & 257 & 125 & $<0.001$ \\
Hyperlipidaemia, n (\%) & 194 & 152 & 0.0003 \\
Total cholesterol (mg/dL) & $4.94 \pm 1.16$ & $5.01 \pm 1.06$ & $<0.001$ \\
Triglycerides (mmol/L) & $1.64 \pm 0.98$ & $1.40 \pm 0.81$ & $<0.001$ \\
HDL (mmol/L) & $1.24 \pm 0.36$ & $1.47 \pm 0.39$ & $<0.001$ \\
LDL (mmol/L) & $3.01 \pm 0.98$ & $3.04 \pm 0.93$ & 0.095 \\
HCY (mmol/L) & $13.52 \pm 5.67$ & $10.84 \pm 3.05$ & $<0.001$ \\
\hline
\end{tabular}


Table 2. Genotype and allele frequencies of MMP9 polymorphisms between IS patients and controls, and corresponding ORs for IS. Adjusted for age, gender, smoking, hypertension, diabetes mellitus and hyperlipidaemia. *False discovery rate-adjusted P value for multiple hypotheses testing using the BenjaminiHochberg method. $\mathrm{P}<0.05$ is indicated in bold font

\begin{tabular}{|c|c|c|c|c|}
\hline Genotype \& Allele & $\begin{array}{c}\text { IS patients } \\
\mathrm{n}=1274(\%)\end{array}$ & $\begin{array}{c}\text { Controls } \\
\mathrm{n}=1258(\%)\end{array}$ & AOR (95\%CI) & $P$ value \\
\hline \multicolumn{5}{|l|}{ rs17576 } \\
\hline GG & $751(58.9)$ & $730(58.0)$ & & 0.89 \\
\hline GA & $457(35.9)$ & $461(36.7)$ & & \\
\hline $\mathrm{AA}$ & $66(5.2)$ & $67(5.3)$ & & \\
\hline Dominant model GG vs. GA/AA & $523(41.1)$ & $528(42.0)$ & $0.96(0.82-1.13)$ & 0.64 \\
\hline Recessive model GG/GA vs. AA & $1208(94.8)$ & $1191(94.7)$ & $0.97(0.68-1.38)$ & 0.86 \\
\hline G allele & $1959(76.9)$ & $1921(76.4)$ & 1.000 & \\
\hline A allele & $589(23.1)$ & $595(23.6)$ & $0.97(0.85-1.11)$ & 0.65 \\
\hline \multicolumn{5}{|l|}{ rs3787268 } \\
\hline GG & $437(34.3)$ & $431(34.3)$ & & 0.80 \\
\hline GA & $630(49.5)$ & $634(50.4)$ & & \\
\hline $\mathrm{AA}$ & $207(16.2)$ & $193(15.3)$ & & \\
\hline Dominant model GG vs. GA/AA & $837(65.7)$ & $827(65.7)$ & $1.00(0.85-1.18)$ & 1.00 \\
\hline Recessive model GG/GA vs. AA & $1067(83.8)$ & $1065(84.7)$ & $1.07(0.86-1.33)$ & 0.53 \\
\hline G allele & $1504(59.0)$ & $1496(59.5)$ & 1.000 & \\
\hline A allele & $1044(41.0)$ & $1020(40.5)$ & $1.02(0.91-1.14)$ & 0.75 \\
\hline \multicolumn{5}{|l|}{ rs3918241 } \\
\hline TT & $986(77.4)$ & $988(78.5)$ & & 0.42 \\
\hline TA & $269(21.1)$ & $258(20.5)$ & & \\
\hline $\mathrm{AA}$ & $19(1.5)$ & $12(1.0)$ & & \\
\hline Dominant model TT vs. TA/AA & $288(22.6)$ & $270(21.5)$ & $1.07(0.89-1.29)$ & 0.49 \\
\hline Recessive model TT/TA vs. AA & $1255(98.5)$ & $1246(99.0)$ & $1.57(0.76-3.25)$ & 0.22 \\
\hline $\mathrm{T}$ allele & $2241(88.0)$ & $2236(88.8)$ & 1.000 & \\
\hline A allele & $307(12.0)$ & $282(11.2)$ & $1.09(0.92-1.29)$ & 0.35 \\
\hline \multicolumn{5}{|l|}{ rs3918242 } \\
\hline $\mathrm{CC}$ & $1002(78.7)$ & 1041(82.8) & & $0.012 *$ \\
\hline CT & 241(18.9) & $202(16.0)$ & & \\
\hline TT & $31(2.4)$ & $15(1.2)$ & & \\
\hline Dominant model CC vs. CT/TT & $272(19.2)$ & $217(17.2)$ & $1.30(1.07-1.59)$ & $0.012^{*}$ \\
\hline Recessive model CC/CT vs. TT & $1243(97.6)$ & $1243(98.8)$ & $2.07(1.11-3.85)$ & $0.019 *$ \\
\hline $\mathrm{C}$ allele & $2245(88.1)$ & $2284(90.8)$ & 1.000 & \\
\hline T allele & $303(11.9)$ & $232(9.2)$ & $1.32(1.11-1.59)$ & $0.0092 *$ \\
\hline
\end{tabular}

IS patients and controls were included in the haplotype analysis. However, no significant associations were observed between these haplotypes and IS (Table 3).

$\begin{array}{lr}\text { The } & \text { association of } \\ \text { MMP9 } & \text { rs3918242 } \\ \text { gene } & \text { polymorphism } \\ \text { with } & \text { demographic }\end{array}$

Table 3. The frequencies of haplotypes of MMP9 gene in patients and controls. ${ }^{a}$ adjusted for age, gender, smoking, hypertension, diabetes mellitus and hyperlipidaemia. All those frequency $<0.05$ will be ignored in analysis

\begin{tabular}{lcccc}
\hline Haplotypes & Case (freq) & Control (freq) & OR (95\%) & P value \\
& MMP9 (rs17576, rs3787268, rs3918241, rs3918242) & \\
\hline A-G-T-C & $459.01(0.182)$ & $527.84(0.212)$ & $0.871(0.756-1.003)$ & 0.0557 \\
G-A-T-C & $919.93(0.365)$ & $888.53(0.356)$ & $1.120(0.993-1.262)$ & 0.0645 \\
G-G-A-C & $242.41(0.096)$ & $239.73(0.096)$ & $1.050(0.869-1.268)$ & 0.615 \\
G-G-T-C & $554.29(0.220)$ & $590.56(0.237)$ & $0.959(0.838-1.097)$ & 0.539 \\
\hline
\end{tabular}

characteristics

The associations of MMP9 rs3918242 gene polymorphisms with demographic characteristics are shown in Table 4. In an analysis stratified by smoking status, an increased risk of IS was associated with the variant genotypes CT and TT at the rs3918242 polymorphism in smoking patients $(\mathrm{P}=0.0052$ for the genotype, and $\mathrm{P}=0.0019$ for the allele). However, no significant interaction was found between $M M P 9$ rs3918242 polymorphism and age, gender, diabetes and hypertension in conferring the risk of IS.

Associations between MMP9 rs3918242 gene polymorphism and stroke subtypes

To explore whether the effects of MMP9 rs3918242 gene polymorphism are confined to a specific subtype or related to overall risk, we further separated the IS patient groups into stroke subgroups based on the CISS system [21]. As shown in Table 5, when the population was stratified according to the CISS classification system, the carriers of the T allele at the 
Table 4. A comparison between the baseline characteristics of the MMP9 rs3918242 genotypes and alleles in the IS patient and control groups. $\mathrm{P}_{G}$ : $\mathrm{P}$ value of the difference in alleles between the case and control groups; $\mathrm{P}_{\mathrm{A}}$ : $\mathrm{P}$ value of the difference in genotype between the case and control groups a adjusted for age, gender, smoking, hypertension, diabetes mellitus and hyperlipidaemia. *False discovery rate-adjusted $\mathrm{P}$ value for multiple hypotheses testing using the Benjamini-Hochberg method. ${ }^{\mathrm{b}} \mathrm{P}<0.05$ is indicated in bold font

\begin{tabular}{|c|c|c|c|c|c|c|c|c|c|c|c|c|}
\hline \multirow[b]{2}{*}{ Characteristics } & \multicolumn{5}{|c|}{ IS patient group } & \multicolumn{4}{|c|}{ Control group } & \multirow[b]{2}{*}{$\begin{array}{c}\text { Allele } \mathrm{n}(\%) \\
\mathrm{T}\end{array}$} & \multirow{2}{*}{$\begin{array}{c}\mathrm{PG}^{\mathrm{a}} \\
\text { value }\end{array}$} & \multirow{2}{*}{$\begin{array}{c}\mathrm{P}_{\mathrm{A}}^{\mathrm{a}} \\
\text { value }\end{array}$} \\
\hline & CC & \multicolumn{2}{|c|}{ Genotype $(\%)$} & & Allele n (\%) & \multicolumn{2}{|c|}{ Genotype n (\%) } & TT & C & & & \\
\hline Age & & & & & & & & & & & & \\
\hline$\geq 65$ years & $509(78.3)$ & $121(18.6)$ & $20(3.1)$ & $1139(87.6)$ & $161(12.4)$ & $525(81.8)$ & $108(16.8)$ & $9(1.4)$ & $1158(90.2)$ & $126(9.8)$ & 0.076 & 0.039 \\
\hline$<65$ years & $493(79.0)$ & $120(19.2)$ & $11(1.8)$ & $1106(88.6)$ & $142(11.4)$ & $516(83.8)$ & $94(15.2)$ & $6(1.0)$ & $1126(91.4)$ & $106(8.6)$ & 0.075 & 0.023 \\
\hline Gender & & & & & & & & & & & & \\
\hline Male & 711(79.9) & $156(17.5)$ & $23(2.6)$ & $1578(88.7)$ & 202(11.3) & $684(83.1)$ & $128(15.6)$ & $11(1.3)$ & $1496(90.9)$ & $150(9.1)$ & 0.087 & 0.032 \\
\hline Female & $291(75.8)$ & $85(22.1)$ & $8(2.1)$ & $667(86.8)$ & 101(13.2) & $357(82.1)$ & $74(17.0)$ & $4(0.9)$ & $788(90.6)$ & $82(9.4)$ & 0.058 & 0.023 \\
\hline Smoking & & & & & & & & & & & & \\
\hline Yes & $469(75.6)$ & $129(20.8)$ & $22(3.5)$ & $1067(83.1)$ & $173(16.9)$ & $316(82.7)$ & $61(16.0)$ & $5(1.3)$ & 693(90.7) & $71(9.3)$ & $0.0052^{*}$ & $0.0019^{*}$ \\
\hline $\begin{array}{l}\text { No } \\
\text { Diabetes }\end{array}$ & 533(81.5) & $112(17.1)$ & $9(1.4)$ & $1178(90.1)$ & $130(9.9)$ & $725(82.8)$ & $141(16.1)$ & $10(1.1)$ & $1591(90.8)$ & $161(9.2)$ & 0.77 & 0.49 \\
\hline Yes & 191(74.3) & $58(22.6)$ & $8(3.1)$ & $440(85.6)$ & $74(14.4)$ & $105(84.0)$ & $18(14.4)$ & $2(1.6)$ & $228(91.2)$ & $22(8.8)$ & 0.11 & 0.036 \\
\hline No & 811(79.7) & $183(18.0)$ & $23(2.3)$ & $1805(88.7)$ & $229(11.3)$ & $936(82.6)$ & $184(16.2)$ & $13(1.2)$ & $2056(90.7)$ & $210(9.3)$ & 0.068 & 0.034 \\
\hline Hypertensi & & & & & & & & & & & & \\
\hline Yes & $595(76.0)$ & $165(21.1)$ & $23(2.9)$ & $1355(86.5)$ & 211(13.5) & $421(79.7)$ & $100(18.9)$ & $7(1.4)$ & $942(89.2)$ & $114(10.8)$ & 0.092 & 0.046 \\
\hline No & $407(82.9)$ & $76(15.5)$ & $8(1.6)$ & $890(90.6)$ & $92(9.4)$ & $620(84.9)$ & $102(14.0)$ & $8(1.1)$ & $1342(91.9)$ & $118(8.1)$ & 0.53 & 0.27 \\
\hline
\end{tabular}

Table 5. The relationship between MMP9 genotypes and IS stratified by CISS classification in IS patients LAA: Large-artery atherosclerosis; PAD: Penetrating artery disease; CS: Cardioembolic Stroke; UE: Undetermined aetiology ${ }^{a}$ adjusted for age, gender, smoking, hypertension, diabetes mellitus and hyperlipidaemia. *False discovery rate-adjusted $\mathrm{P}$ value for multiple hypotheses testing using the Benjamini-Hochberg method

\begin{tabular}{|c|c|c|c|c|c|c|c|}
\hline \multirow{3}{*}{ Value } & \multicolumn{7}{|c|}{ MMP9 rs3918242 } \\
\hline & \multicolumn{3}{|c|}{ Genotype } & P valupa & \multicolumn{2}{|c|}{ Allele } & \multirow{2}{*}{ P value } \\
\hline & $\mathrm{CC}$ & CT & TT & Pvarue ${ }^{a}$ & C & $\mathrm{T}$ & \\
\hline Controls & $1041(82.8)$ & $202(16.0)$ & $15(1.2)$ & & $2284(90.8)$ & $232(9.2)$ & \\
\hline \multicolumn{8}{|l|}{ Cases } \\
\hline LAA ( $n=887)$ & $692(78.6)$ & $173(18.9)$ & $22(2.5)$ & $0.028^{*}$ & $1557(87.8)$ & $217(12.2)$ & $0.0068^{*}$ \\
\hline $\operatorname{PAD}(n=266)$ & $219(80.5)$ & $40(16.9)$ & $7(2.6)$ & 0.264 & $478(89.8)$ & $54(10.1)$ & 0.51 \\
\hline $\operatorname{CS}(n=54)$ & $40(74.0)$ & $13(24.1)$ & $1(1.9)$ & 0.264 & $93(86.1)$ & $15(13.9)$ & 0.227 \\
\hline UE $(n=67)$ & $51(76.1)$ & $15(22.4)$ & $1(1.5)$ & 0.272 & $117(87.3)$ & $17(12.7)$ & 0.227 \\
\hline
\end{tabular}

MMP9 rs3918242 gene polymorphism appeared to have a higher risk of stroke of the large artery atherosclerosis (LAA) subtype compared with the controls $(\mathrm{P}=0.0068)$. No statistical associations were observed between the MMP9 rs3918242 gene polymorphism and other stroke subtypes in the healthy controls.

The serum levels of MMP9 based on the MMP9 rs3918242 polymorphisms

The serum levels of MMP9 measured in 124 IS patients and 120 controls are presented in Fig. 1. Generally, the serum MMP9 levels were significantly higher in the IS patients than in the controls $(\mathrm{P}<0.05)$ (Fig. 1). Moreover, when the samples were stratified according to the MMP9 rs3918242 genotypes, the serum MMP9 levels were significantly higher in patients with the CT and TT genotypes than in those with the CC genotypes at the rs3918242 polymorphism $(\mathrm{P}=0.031)$ (Fig. 1A). However, in the healthy controls, no significant differences in serum MMP9 levels were detected among the controls with different genotypes (Fig. 1A). We also determined the serum MMP9 levels in the IS patients and controls who were stratified according to smoking status. A significant increase in the serum MMP9 levels was found in the smoking patients $(\mathrm{P}=0.022)$.

Association of the MMP9 rs3918242 polymorphisms with the infarct volume

Associations of the MMP9 rs3918242 polymorphisms with the actual volumetric measurements of infarct volume by DWI in 115 IS patients were explored, and the results 


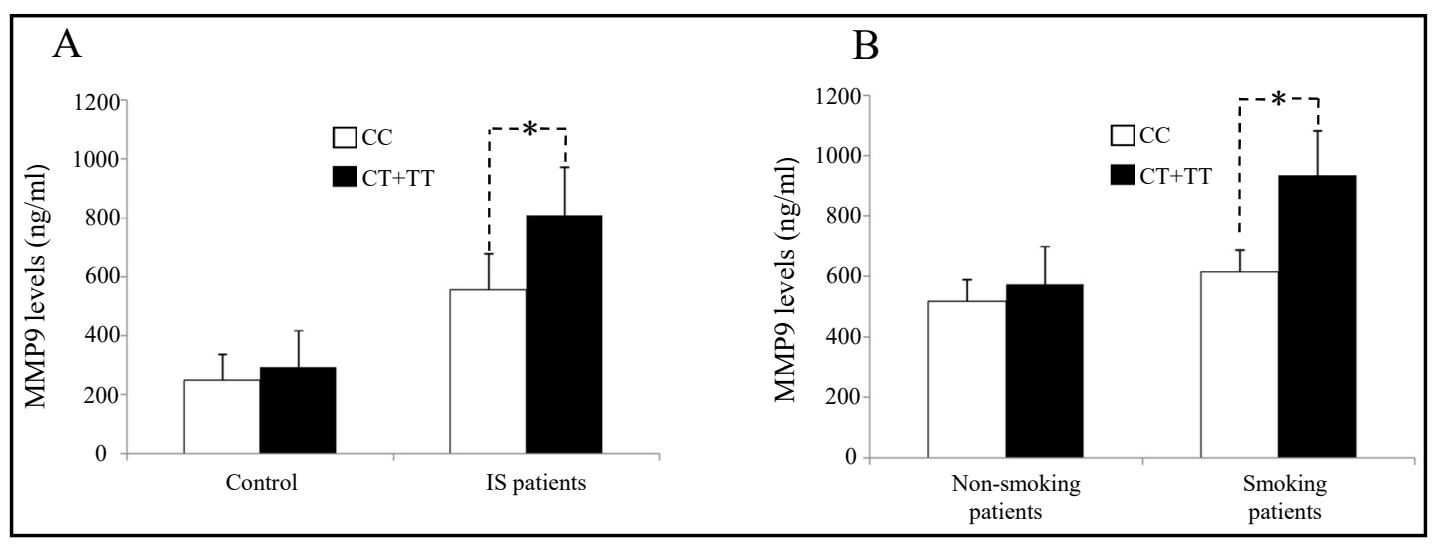

Fig. 1. (A) The serum MMP9 levels in the IS patients $(n=124)$ and the controls $(n=120)$ stratified based on the MMP9 rs3918242 genotypes. The blank box represents the rs3918242 CC genotype (n=98 for the IS patients and $n=99$ for the controls) and the black box represents the rs3918242 CT + TT genotype ( $n=26$ for the IS patients and $\mathrm{n}=21$ for the controls). ${ }^{*} \mathrm{P}=0.031$ when comparing the serum MMP9 levels in IS patients between the CC genotype and the CT + TT genotype. (B) The serum MMP9 levels in the IS patients stratified according to smoking status and the rs3918242 genotype. The blank box represents the rs3918242 CC genotype ( $n=45$ for the smoking patients and $n=52$ for the non-smoking patients) and the black box represents the rs3918242 CT + TT genotype $(n=15$ for the smoking patients and $n=12$ for the non-smoking patients). ${ }^{*} \mathrm{P}=0.022$. The serum MMP9 levels in the IS patients and the healthy individuals were measured using ELISA. The data are shown as the mean \pm SD. An asterisk indicates $\mathrm{P}<0.05$.

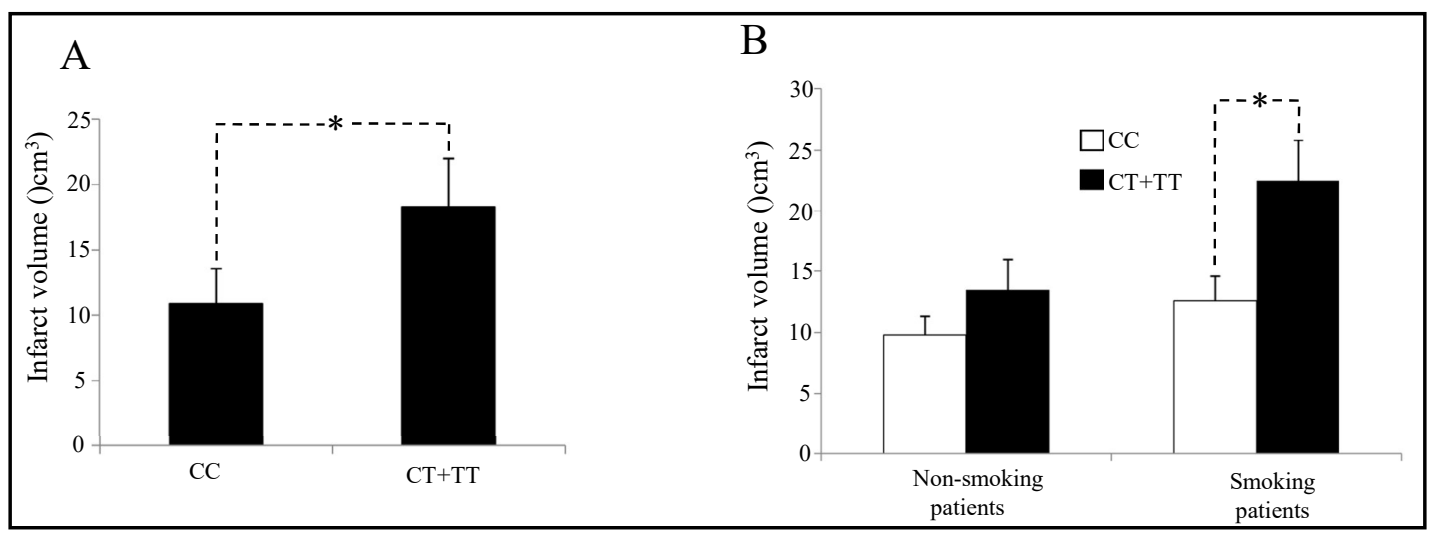

Fig. 2. (A)The mean infarct volumes \pm SD in the IS patients stratified based on the MMP9 rs3918242 genotypes ( $\mathrm{n}=91$ for the patients with CC genotypes and $\mathrm{n}=24$ for the patients with CT + TT genotypes). ${ }^{*} \mathrm{P}$ $=0.036$. (B) The mean infarct volumes \pm SD in the IS patients stratified according to smoking status and the presence of the mutated allele. The blank box represents the rs3918242 CC genotype ( $n=42$ for the smoking patients and $n=49$ for the non-smoking patients) and the black box represents the rs3918242 CT + TT genotype ( $\mathrm{n}=14$ for the smoking patients and $\mathrm{n}=10$ for the non-smoking patients). ${ }^{*} \mathrm{P}=0.027$. The data are shown as the mean \pm SD. Correlations between the genotypes of the MMP9 rs3918242 polymorphism and the DWI infarct volume were assessed using analysis of variance (ANOVA). An asterisk indicates $\mathrm{P}<0.05$.

are shown in Fig. 2. The mean infarct volumes in the IS patients with the MMP9 rs3918242 genotypes $(\mathrm{CT}+\mathrm{TT})$ were significantly higher than those in patients with the major CC genotype $(\mathrm{P}=0.036)($ Fig. $2 \mathrm{~A})$. When the IS patients were stratified by smoking status, a significant increase in the infarct volumes was found in the smoking patients with the variant rs3918242 genotypes (CT + TT) $(\mathrm{P}=0.027)$ (Fig. 2B). 


\section{Cellular Physiology Cell Physiol Biochem 2018;49:2188-2199

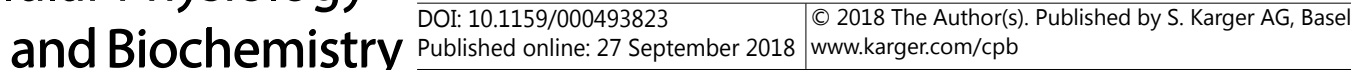 \\ Li et al.: MMP9 Polymorphisms and Ischaemic Stroke}

\section{Discussion}

In this hospital-based case-control study, we investigated the association of four important polymorphisms of the MMP9 gene, including rs17576, rs3787268, rs3918241 and rs3918242, with the risk of IS in a relatively large southern Chinese population, and we observed a significant association between the MMP9 rs3918242 polymorphism and the risk of IS. The presence of the MMP9 rs3918242 T allele conferred a higher risk of developing IS, which may hav e resulted from the interaction with smoking. Further stratification revealed that the variant $\mathrm{T}$ allele of the $M M P 9$ rs3918242 polymorphism was associated with a higher risk of IS of the LAA subtype. The serum MMP9 levels were significantly higher in IS patients with the variant CT and TT alleles of the MMP9 rs3918242 polymorphism than in those carrying the major CC genotype. Additionally, patients with the variant genotypes (CT + TT) of the MMP9 polymorphism had higher infarct volumes than those carrying the major CC genotype.

MMPs regulate many aspects of cellular activity, with functions ranging from ECM degradation, cell proliferation, adhesion, and migration to release of ECM-sequestered molecules by proteolysis, shedding of cell-surface proteins that transduce signals from the ECM [27], and activation of pro-inflammatory cytokines [28]. MMP9 has been documented to play critical roles in blood-brain barrier integrity, tissue repair and remodelling following stroke [29]. Following stroke, increased levels of MMP9 have been detected in both peripheral and central cells, including neurons, glia, endothelial cells and neutrophils [30, 31]. Animal studies indicated that increased expression of pro/active MMP9 was detected within hours to days following stroke in non-human primates [32], rats [33], and mice [34]. Clinical studies also demonstrated that MMP9 is elevated in the serum of stroke patients and is correlated with a worsened outcome $[35,36]$. These lines of evidence have led us to formulate the hypothesis that MMP9 could be of pathogenic importance in IS.

Several previous studies have examined the role of MMP9 genetic polymorphisms and the susceptibility to stroke, but the results are inconclusive. Buraczynska et al. [19] and Zhang et al. [37] indicated that MMP9 $-1562 \mathrm{C} / \mathrm{T}$ polymorphism was significantly associated with risk of stroke in the population studied. Kaplan et al. [38] suggested that MMP9 haplotypes or SNPs were not associated with myocardial infarction or stroke. Pollanen et al. confirmed the correlation between the $-1562 \mathrm{C} / \mathrm{T}$ polymorphism of the MMP9 gene and the instability and rupture of atherosclerotic plaques [39]. In our present study, we found that the variant T allele of MMP9 rs3918242 was associated with the risk of developing IS in a Chinese population. Carriers of the MMP9 rs3918242 T allele showed a significantly greater prevalence of IS than subjects with the CC genotype. Further large-scale studies are needed to verify the results of our findings.

The pathogenesis of IS is the result of interactions between genetic predispositions and environmental factors. As an independent modifiable risk factor for cardiovascular disease, cigarette smoke doubles the risk of stroke [40]. Smoking is estimated to be responsible for $12 \%$ to $37 \%$ of all stroke events. Individuals who smoke approximately 20 cigarettes per day are six times more likely to have a stroke than non-smokers [41]. Smoking increases the risk for vascular disease by induction of a procoagulant state and acceleration of atherosclerosis [41]. In our present study, when the MMP9 rs3918242 genotype and allele frequency were further stratified by age, gender, smoking status, diabetes, and hypertension, an increased risk of IS was found in smoking subgroups of the IS patients compared to the controls. Therefore, it is highly speculated that environmental risk factors and smoking may interplay with the MMP9 genetic predisposition in the present study.

The upregulation of MMP9 was revealed to be involved in the development and progression of a number of vascular diseases [13, 36, 42]. The -1562C/T polymorphism in the promoter region of the $M M P 9$ gene abolishes the DNA-protein interaction, resulting in higher activity of the T-allelic promoter [14]. Thus, the -1562C/T polymorphism may affect the expression of MMP9 and contribute to the occurrence of IS. In the present study, we found that individuals carrying the mutated rs3918242 $\mathrm{T}$ allele expressed higher MMP9 


\section{Cellular Physiology Cell Physiol Biochem 2018;49:2188-2199 and Biochemistry \begin{tabular}{c|c|c|} 
DOI: 10.1159/000493823 & $\begin{array}{l}\text { O } 2018 \text { The Author(s). Published by S. Karger AG, Basel } \\
\text { www.karger.com/cpb }\end{array}$
\end{tabular} \\ Li et al.: MMP9 Polymorphisms and Ischaemic Stroke}

levels when compared with populations carrying the CC genotype. Given the key role of MMP9 in vascular damage, it is conceivable that in the individuals with the rs3918242 T allele, increased serum MMP9 levels may result in degradation of a number of components of the extracellular matrix, which may cause subsequent vascular remodelling. Our findings also indicated a significant increase in the serum MMP9 levels in smoking patients with the variant rs3918242 T allele. Cigarette smoke extract exposure induced increased MMP2 and MMP9 both in vitro and in vivo [43, 44]. Snitker et al. reported that MMP9 level in the blood was significantly higher in current smokers compared to never and former smokers [45]. Wang et al. described that a smoker with $-1562 \mathrm{C} / \mathrm{T}$ or TT genotype was associated with a 1.31-fold risk of MI compared with a nonsmoker with -1562CC genotype, and the multiple logistic regression analysis showed that the interaction between smoking and the $-1562 \mathrm{~T}$ allele resulted in a significant 4.42-fold increased risk of MI [46]. From the observation of this evidence and our findings, it is highly likely that smokers with the rs3918242 T allele will be more susceptible to increased MMP9 release, thereby contributing to the development of IS.

Accumulating evidence confirmed that the plasma level of MMP9 was related to neurological worsening, infarct volumes, and haemorrhagic transformation [47, 48].In animal studies, it was shown that plasma MMP9 release increased the size of the brain infarct area [49]. In a study related to IS, a strong correlation was detected between plasma MMP9 level and size of infarct area in patients treated with t-PA [50]. Montaner et al. confirmed a positive correlation between plasma MMP9 level and infarct volume [51]. In the present study, we found that patients carrying the variant genotypes (CT and TT) of the rs3918242 polymorphism have higher infarct volumes than those carrying the major CC genotype. In addition, we confirmed that individuals with the variant genotypes (CT and TT) of the rs3918242 polymorphism had significantly higher infarct volumes than those carrying the major CC genotype in smoking patients. Considering the effects of increased MMP9 expression on IS development, it is conceivable that smokers with T allele of MMP9 rs3918242 may have increased MMP9 expression, thereby contributing to higher infarct volumes.

This case-control study had some limitations that should be accounted for when interpreting the results. First, potential bias, including information bias, selection bias and confounding bias, cannot be entirely excluded. Specifically, control subjects were determined free of IS by medical history, or a lack of examination by CT or MRI. Without confirmation of imaging examinations, some control subjects may have been affected by silent stroke, which may reduce the statistical power. Second, some other functional polymorphisms may influence the expression of MMP9 and contribute to the development of IS, and their combined effects must be studied to better predict the occurrence, severity, and outcome of IS. Third, the other risk factors in the study group, such as age, gender, smoking, hypertension, diabetes or hyperlipidaemia, may have complicated the association between $M M P 9$ polymorphisms and IS. Larger prospective studies are necessary to fully elucidate the role of these polymorphisms in IS.

\section{Conclusion}

In conclusion, our findings support the existence of an association between the MMP9 rs3918242 polymorphism and the risk of developing IS in a southern Chinese population. In particular, smokers carrying the rs3918242 T allele of MMP9, which is associated with increased MMP9 levels, may run a higher risk of developing IS. Our study may provide clues for the evaluation of individual susceptibility to IS and for the development of effective measures to control and prevent IS. 


\section{Cellular Physiology Cell Physiol Biochem 2018;49:2188-2199 and Biochemistry \begin{tabular}{l|l} 
DOI: 10.1159/000493823 & 2018 The Author(s). Published by S. Karger AG, Basel \\
(c) & www.kargercom/cpb
\end{tabular} \\ Published online: 27 September 2018 www.karger.com/cp}

\section{Acknowledgements}

This work was supported by funding from the National Nature Science Foundation of China (grant numbers 81571157, 81300929, 81670252 and 81471294).

\section{Disclosure Statement}

The authors have no actual or potential conflicts of interest related to this manuscript. Appropriate approval was obtained, and appropriate procedures were followed concerning human subjects.

\section{References}

1 Feigin VL, Norrving B, Mensah GA: Global Burden of Stroke. Circ Res 2017;120:439-448.

2 Goldstein LB, Adams R, Becker K, Furberg CD, Gorelick PB, Hademenos G, Hill M, Howard G, Howard VJ, Jacobs B, Levine SR, Mosca L, Sacco RL, Sherman DG, Wolf PA, del Zoppo GJ: Primary prevention of ischemic stroke: A statement for healthcare professionals from the Stroke Council of the American Heart Association. Stroke 2001;32:280-299.

3 Liu D, Liu L, Song Z, Hu Z, Liu J, Hou D: Genetic Variations of Oxidative Stress Related Genes ALOX5, ALOX5AP and MPO Modulate Ischemic Stroke Susceptibility Through Main Effects and Epistatic Interactions in a Chinese Population. Cell Physiol Biochem 2017;43:1588-1602.

-4 He W, Lu M, Li G, Sun Z, Liu D, Gu L: Methylene Tetrahydrofolate Reductase (MTHFR) rs868014 Polymorphism Regulated by miR-1203 Associates with Risk and Short Term Outcome of Ischemic Stroke. Cell Physiol Biochem 2017;41:701-710.

-5 Yue YH, Bai XD, Zhang HJ, Li YM, Hu L, Liu LY, Mao JP, Yang XY, Dila NM: Gene Polymorphisms Affect the Effectiveness of Atorvastatin in Treating Ischemic Stroke Patients. Cell Physiol Biochem 2016;39:630-638.

6 Galis ZS, Khatri JJ: Matrix metalloproteinases in vascular remodeling and atherogenesis: the good, the bad, and the ugly. Circ Res 2002;90:251-262.

7 Newby AC: Metalloproteinase expression in monocytes and macrophages and its relationship to atherosclerotic plaque instability. Arterioscler Thromb Vasc Biol 2008;28:2108-2114.

$\$ 8$ Newby AC: Dual role of matrix metalloproteinases (matrixins) in intimal thickening and atherosclerotic plaque rupture. Physiol Rev 2005;85:1-31.

9 Foerch C, Montaner J, Furie KL, Ning MM, Lo EH: Invited article: searching for oracles? Blood biomarkers in acute stroke. Neurology 2009;73:393-399.

10 Romanic AM, White RF, Arleth AJ, Ohlstein EH, Barone FC: Matrix metalloproteinase expression increases after cerebral focal ischemia in rats: inhibition of matrix metalloproteinase- 9 reduces infarct size. Stroke 1998;29:1020-1030.

11 Galis ZS, Sukhova GK, Lark MW, Libby P: Increased expression of matrix metalloproteinases and matrix degrading activity in vulnerable regions of human atherosclerotic plaques. J Clin Invest 1994;94:24932503.

12 Loftus IM, Naylor AR, Goodall S, Crowther M, Jones L, Bell PR, Thompson MM: Increased matrix metalloproteinase- 9 activity in unstable carotid plaques. A potential role in acute plaque disruption. Stroke 2000;31:40-47.

13 Zhong C, Yang J, Xu T, Xu T, Peng Y, Wang A, Wang J, Peng H, Li Q Ju Z, Geng D, Zhang Y, He J, Investigators C: Serum matrix metalloproteinase-9 levels and prognosis of acute ischemic stroke. Neurology 2017;89:805812.

14 Zhang B, Henney A, Eriksson P, Hamsten A, Watkins H, Ye S: Genetic variation at the matrix metalloproteinase-9 locus on chromosome 20q12.2-13.1. Hum Genet 1999;105:418-423.

15 Zhang B, Ye S, Herrmann SM, Eriksson P, de Maat M, Evans A, Arveiler D, Luc G, Cambien F, Hamsten A, Watkins $\mathrm{H}$, Henney AM: Functional polymorphism in the regulatory region of gelatinase $B$ gene in relation to severity of coronary atherosclerosis. Circulation 1999;99:1788-1794. 


\section{Cellular Physiology Cell Physiol Biochem 2018;49:2188-2199 \begin{tabular}{l|l|l} 
and Biochemistry 10.1159/000493823 & $\begin{array}{l}\text { @ } 2018 \text { The Author(s). Published by S. Karger AG, Basel } \\
\text { www.karger.com/cpb }\end{array}$ \\
\hline
\end{tabular}}

Li et al.: MMP9 Polymorphisms and Ischaemic Stroke

16 Blankenberg S, Rupprecht HJ, Poirier O, Bickel C, Smieja M, Hafner G, Meyer J, Cambien F, Tiret L, AtheroGene I: Plasma concentrations and genetic variation of matrix metalloproteinase 9 and prognosis of patients with cardiovascular disease. Circulation 2003;107:1579-1585.

17 Li J, Lu H, Tao F, Zhou H, Feng G, He L, Zhou L: Meta-analysis of MMP9-562C/T and the risk of coronary heart disease. Cardiology 2013;124:53-59.

18 Juan Z, Wei-Guo Z, Heng-Liang S, Da-Guo W: Association of Matrix Metalloproteinase 9 C-1562T Polymorphism with Genetic Susceptibility to Myocardial Infarction: A Meta-Analysis. Curr Ther Res Clin Exp 2015;77:40-45.

-19 Buraczynska K, Kurzepa J, Ksiazek A, Buraczynska M, Rejdak K: Matrix Metalloproteinase-9 (MMP-9) Gene Polymorphism in Stroke Patients. Neuromolecular Med 2015;17:385-390.

20 Wang X, Shi LZ: Association of matrix metalloproteinase-9 C1562T polymorphism and coronary artery disease: a meta-analysis. J Zhejiang Univ Sci B 2014;15:256-263.

21 Gao S, Wang YJ, Xu AD, Li YS, Wang DZ: Chinese ischemic stroke subclassification. Front Neurol 2011;2:6.

-22 Whelton PK, Carey RM, Aronow WS, Casey DE, Jr., Collins KJ, Dennison Himmelfarb C, DePalma SM, Gidding S, Jamerson KA, Jones DW, MacLaughlin EJ, Muntner P, Ovbiagele B, Smith SC, Jr., Spencer CC, Stafford RS, Taler SJ, Thomas RJ, Williams KA, Sr., Williamson JD, Wright JT, Jr.: 2017 ACC/AHA/AAPA/ABC/ACPM/AGS/ APhA/ASH/ASPC/NMA/PCNA Guideline for the Prevention, Detection, Evaluation, and Management of High Blood Pressure in Adults: A Report of the American College of Cardiology/American Heart Association Task Force on Clinical Practice Guidelines. Hypertension 2018;71:e13-e115.

-23 Sheikhvatan M, Boroumand MA, Behmanesh M, Ziaee S: Association of R279Q and C1562T polymorphisms of matrix metalloproteinase 9 gene and increased risk for myocardial infarction in patients with premature coronary artery disease. J Clin Lab Anal 2017;10.1002/jcla.22218

-24 Yang J, Lin S, Zhou J, Wu B, Dong W, Arima H, Liu H, Zhang J, Li J, Liu M, Chengdu Stroke R, Nanjing First Hospital Stroke Registry i: Genetic variations of MMP9 gene and intracerebral hemorrhage outcome: a cohort study in Chinese Han population. J Neurol Sci 2014;343:56-59.

25 Li Y, Yang C, Ma G, Cui L, Gu X, Chen Y, Zhao B, Wang H, Li K: Analysis of ADAM17 polymorphisms and susceptibility to sporadic abdominal aortic aneurysm. Cell Physiol Biochem 2014;33:1426-1438.

-26 Buck BH, Liebeskind DS, Saver JL, Bang OY, Starkman S, Ali LK, Kim D, Villablanca JP, Salamon N, Yun SW, Razinia T, Ovbiagele B: Association of higher serum calcium levels with smaller infarct volumes in acute ischemic stroke. Arch Neurol 2007;64:1287-1291.

27 Cunningham LA, Wetzel M, Rosenberg GA: Multiple roles for MMPs and TIMPs in cerebral ischemia. Glia 2005;50:329-339.

28 Candelario-Jalil E, Yang Y, Rosenberg GA: Diverse roles of matrix metalloproteinases and tissue inhibitors of metalloproteinases in neuroinflammation and cerebral ischemia. Neuroscience 2009;158:983-994.

-29 Lenglet S, Montecucco F, Mach F: Role of matrix metalloproteinases in animal models of ischemic stroke. Curr Vasc Pharmacol 2015;13:161-166.

30 Rosenberg GA: Matrix metalloproteinases in neuroinflammation. Glia 2002;39:279-291.

-31 Gasche Y, Soccal PM, Kanemitsu M, Copin JC: Matrix metalloproteinases and diseases of the central nervous system with a special emphasis on ischemic brain. Front Biosci 2006;11:1289-1301.

-32 Heo JH, Lucero J, Abumiya T, Koziol JA, Copeland BR, del Zoppo GJ: Matrix metalloproteinases increase very early during experimental focal cerebral ischemia. J Cereb Blood Flow Metab 1999;19:624-633.

-33 Justicia C, Panes J, Sole S, Cervera A, Deulofeu R, Chamorro A, Planas AM: Neutrophil infiltration increases matrix metalloproteinase- 9 in the ischemic brain after occlusion/reperfusion of the middle cerebral artery in rats. J Cereb Blood Flow Metab 2003;23:1430-1440.

-34 Fujimura M, Gasche Y, Morita-Fujimura Y, Massengale J, Kawase M, Chan PH: Early appearance of activated matrix metalloproteinase- 9 and blood-brain barrier disruption in mice after focal cerebral ischemia and reperfusion. Brain Res 1999;842:92-100.

-35 Copin JC, Goodyear MC, Gidday JM, Shah AR, Gascon E, Dayer A, Morel DM, Gasche Y: Role of matrix metalloproteinases in apoptosis after transient focal cerebral ischemia in rats and mice. Eur J Neurosci 2005;22:1597-1608.

-36 Ning M, Furie KL, Koroshetz WJ, Lee H, Barron M, Lederer M, Wang X, Zhu M, Sorensen AG, Lo EH, Kelly PJ: Association between tPA therapy and raised early matrix metalloproteinase- 9 in acute stroke. Neurology 2006;66:1550-1555. 


\section{Cellular Physiology Cell Physiol Biochem 2018;49:2188-2199

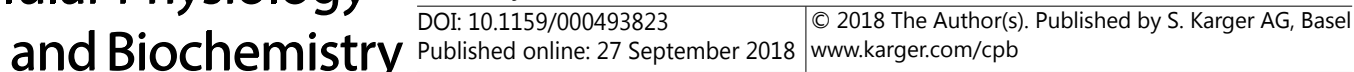

Li et al.: MMP9 Polymorphisms and Ischaemic Stroke

-37 Zhang X, Cao X, Xu X, Li A, Xu Y: Correlation between the -1562C/T polymorphism in the matrix metalloproteinase-9 gene and hemorrhagic transformation of ischemic stroke. Exp Ther Med 2015;9:10431047.

-38 Kaplan RC, Smith NL, Zucker S, Heckbert SR, Rice K, Psaty BM: Matrix metalloproteinase-3 (MMP3) and MMP9 genes and risk of myocardial infarction, ischemic stroke, and hemorrhagic stroke. Atherosclerosis 2008;201:130-137.

-39 Pollanen PJ, Karhunen PJ, Mikkelsson J, Laippala P, Perola M, Penttila A, Mattila KM, Koivula T, Lehtimaki T: Coronary artery complicated lesion area is related to functional polymorphism of matrix metalloproteinase 9 gene: an autopsy study. Arterioscler Thromb Vasc Biol 2001;21:1446-1450.

$>40$ Kernan WN, Ovbiagele B, Black HR, Bravata DM, Chimowitz MI, Ezekowitz MD, Fang MC, Fisher M, Furie KL, Heck DV, Johnston SC, Kasner SE, Kittner SJ, Mitchell PH, Rich MW, Richardson D, Schwamm LH, Wilson JA, American Heart Association Stroke Council CoC, Stroke Nursing CoCC, Council on Peripheral Vascular D: Guidelines for the prevention of stroke in patients with stroke and transient ischemic attack: a guideline for healthcare professionals from the American Heart Association/American Stroke Association. Stroke 2014;45:2160-2236.

-41 Epstein KA, Viscoli CM, Spence JD, Young LH, Inzucchi SE, Gorman M, Gerstenhaber B, Guarino PD, Dixit A, Furie KL, Kernan WN, Investigators IT: Smoking cessation and outcome after ischemic stroke or TIA. Neurology 2017;89:1723-1729.

-42 Montaner J, Molina CA, Monasterio J, Abilleira S, Arenillas JF, Ribo M, Quintana M, Alvarez-Sabin J: Matrix metalloproteinase-9 pretreatment level predicts intracranial hemorrhagic complications after thrombolysis in human stroke. Circulation 2003;107:598-603.

43 Ghosh A, Pechota LV, Upchurch GR, Jr., Eliason JL: Cross-talk between macrophages, smooth muscle cells, and endothelial cells in response to cigarette smoke: the effects on MMP2 and 9. Mol Cell Biochem 2015;410:75-84.

44 Ghosh A, Pechota A, Coleman D, Upchurch GR, Jr., Eliason JL: Cigarette smoke-induced MMP2 and MMP9 secretion from aortic vascular smooth cells is mediated via the Jak/Stat pathway. Hum Pathol 2015;46:284294.

45 Snitker S, Xie K, Ryan KA, Yu D, Shuldiner AR, Mitchell BD, Gong DW: Correlation of circulating MMP-9 with white blood cell count in humans: effect of smoking. PLoS One 2013;8:e66277.

46 Wang L, Ma YT, Xie X, Yang YN, Fu ZY, Li XM, Liu F, Huang Y, Ma X, Chen BD, Yuan S, Sun MH, Peng X, Wang BZ: Interaction between MMP-9 gene polymorphisms and smoking in relation to myocardial infarction in a Uighur population. Clin Appl Thromb Hemost 2012;18:72-78.

47 Montaner J, Alvarez-Sabin J, Molina C, Angles A, Abilleira S, Arenillas J, Gonzalez MA, Monasterio J: Matrix metalloproteinase expression after human cardioembolic stroke: temporal profile and relation to neurological impairment. Stroke 2001;32:1759-1766.

48 Montaner J, Alvarez-Sabin J, Molina CA, Angles A, Abilleira S, Arenillas J, Monasterio J: Matrix metalloproteinase expression is related to hemorrhagic transformation after cardioembolic stroke. Stroke 2001;32:2762-2767.

49 Lee SR, Tsuji K, Lee SR, Lo EH: Role of matrix metalloproteinases in delayed neuronal damage after transient global cerebral ischemia. J Neurosci 2004;24:671-678.

$\rightarrow 50$ Rosell A, Alvarez-Sabin J, Arenillas JF, Rovira A, Delgado P, Fernandez-Cadenas I, Penalba A, Molina CA, Montaner J: A matrix metalloproteinase protein array reveals a strong relation between MMP-9 and MMP13 with diffusion-weighted image lesion increase in human stroke. Stroke 2005;36:1415-1420.

51 Montaner J, Rovira A, Molina CA, Arenillas JF, Ribo M, Chacon P, Monasterio J, Alvarez-Sabin J: Plasmatic level of neuroinflammatory markers predict the extent of diffusion-weighted image lesions in hyperacute stroke. J Cereb Blood Flow Metab 2003;23:1403-1407. 